\title{
In ovo administration of CpG ODN induces expression of immune response genes in neonatal chicken spleen
}

\author{
Joanna Sajewicz-Krukowska, Monika Olszewska-Tomczyk, \\ Katarzyna Domańska-Blicharz \\ Department of Poultry Diseases, \\ National Veterinary Research Institute, 24-100 Pulawy, Poland \\ joanna.sajewicz@piwet.pulawy.pl
}

Received: June 1, 2017

Accepted: October 6, 2017

\begin{abstract}
Introduction: Due to their immunostimulatory properties TLR ligands are used prophylactically to protect against a variety of viral and bacterial pathogens in mammals. Knowledge of the molecular and functional aspects of TLRs is essential for a better understanding of the immune system and resistance to diseases in birds. For that reason, this study attempted to determine the impact of TLR21 stimulation by its synthetic ligand (CpG ODN, class B) on the chicken immune system. Material and Methods: Sixty embryonated chicken eggs were randomly allocated into three groups (control and two experimental groups). On day 18 of embryonic development, chickens in one experimental group were administered in ovo a low dose of CpG ODN and the birds of the second experimental group were given a high dose of the ligand. Spleens were collected at 1, 2, 5, and 10 days post-hatching (dph) for analysis of IFN- $\alpha$, IFN- $\beta$, IFN- $\gamma$, IL-6, and IL-10 expression using qRT-PCR. Results: Significant differences were observed in mRNA expression levels of all the measured cytokines associated with the modulation and regulation of the immune response at different time points. Conclusion: The obtained data clearly demonstrate that immune response induction takes place after in ovo administration of class B CpG ODN, and that the ligand has the ability to induce cytokine responses in neonatal chicken spleen.
\end{abstract}

Keywords: chicken, chTLR21, CpG ODN, immunomodulation, cytokines.

\section{Introduction}

The immune system of birds is considered an important model in immunology. The basic principles of the avian immune system are very similar to their mammalian counterparts. Comprehension of the immune system's mechanisms is essential for a better understanding of resistance to diseases in birds.

Recent findings have clearly demonstrated that the components of the innate immune system may also have at least some of the features of the adaptive immune system (16). This integration and mutual infiltration give the immune response flexibility and resistance, and thus provide protection against various pathogens. Through the stimulation of the innate immune system with various compounds, cellular activation and cytokine production can be obtained, protecting chickens against viral pathogens.
Immune cells involved in the mechanisms of the innate immune response have the ability to distinguish self-antigens from foreign ones due to their specialised receptors. These receptors include highly conserved ligand-binding proteins, namely toll-like receptors (TLRs), which are present in several species including mice, humans, and chickens (6). TLRs, belonging to the pattern recognition receptors (PRR), are responsible for recognising the conserved structural motifs derived from a variety of microorganisms, known as pathogenassociated molecular patterns (PAMPs) (26). Binding the suitable ligand to the TLR triggers a signalling cascade that leads to the activation of many adaptor proteins, transcription factors, and consequently the production of proinflammatory cytokines, chemokines, and defensive molecules. Most vertebrates encode from 10 to 13 different TLRs. TLRs $1-10$ have been identified in humans, while TLRs 1-13 have been 
identified in mice. Recent studies on TLR expression in chickens confirmed their evolutionarily conserved nature and identified 10 different TLR genes (18). Six of these (TLR 2a, 2b, 3, 4, 5, and 7) are clear orthologues of TLRs found in mammals (4). Chicken TLR21 (chTLR21) does not have a mammalian orthologue; however, it is sensitive and responsive to unmethylated cytosine triphosphate deoxynucleotidephosphodiester-guanine triphosphate deoxynucleotide (CpG) DNA similarly to the mammalian TLR9 ligand. Synthetic oligodeoxynucleotides containing unmethylated $\mathrm{CpG}$ motifs (CpG ODN) are similar to CpG DNA from microorganisms and are able to cause series of immunostimulatory effects in vertebrates. In experimental research this phenomenon is used to increase the resistance of the host through the stimulation of signal transduction from TLRs by synthetic analogues of their natural ligands (33).

In vitro studies showed induction of interleukin- $1 \mathrm{~b}$ (IL-1b), interleukin-6 (IL-6), interferons (IFNs), and nitric oxide (NO) in chicken peripheral blood mononuclear cells (PBMC) and macrophages treated with CpG ODN (9). Although the immune response mediated via TLR has been fairly well studied in vitro, there are few studies regarding chickens' response to $\mathrm{CpG}$ in vivo. Immunomodulation with the use of $\mathrm{CpG}$ ODN was shown in 1-day-old and adult birds $(1,18)$. However, its mechanism has not yet been well characterised in neonatal birds. Moreover, it is unknown how the response kinetics changes after in ovo administration of $\mathrm{CpG}$ in post-hatch chicks and how long these changes last.

Due to their immunostimulatory properties, TLR ligands are used prophylactically to protect against a variety of viral and bacterial pathogens in mammals (29, 32). In ovo delivery of $\mathrm{CpG}$ ODN induced protection against $E$. coli and Salmonella typhimurium in chickens after hatching $(11,38)$. In addition, $\mathrm{CpG}$ ODN application in one-day-old chicks significantly reduced mortality and degree of internal organs colonisation of birds experimentally infected with Salmonella $(14,37)$. Furthermore, it has been shown that TLR stimulation with their ligands inhibits the replication of certain viruses, e.g. avian influenza virus (AIV), Marek's disease virus (MDV), and infectious bronchitis virus (IBV) $(8,30,37)$. It has also been proven that in ovo use of $\mathrm{CpG}$ ODN stimulated the primary immune response against Salmonella enteritidis, and also reduced intestinal colonisation by these bacteria (25). However, the mechanism of immune modulation and $\mathrm{CpG}$ DNA activity in the antiviral response has not been fully explained.

The aim of the present study was to determine the impact of toll-like receptor TLR21 stimulation by in ovo administration of its synthetic ligand (CpG ODN, class B) on selected parameters (IL-6, IL-10, IFN- $\alpha$, IFN- $\beta$, and IFN- $\gamma$ ) of the post-hatching chicken immune system. Since class B CpG-ODN can induce $\mathrm{B}$-cell proliferation, the spleen was chosen as the target organ for analysis of cytokine expression in neonatal chickens.

\section{Material and Methods}

Animals. Specific-pathogen-free (SPF) embryonic eggs were purchased from Valo BioMedia (Germany) and hatched chicks were maintained in cages at biosafety level 2 animal facility with feed and water $a d$ libitum.

TLR ligand. Synthetic class B CpG ODN (5'-TCGTCGTTGTCGTTTTGTCGTT-3') with phosphorothioate backbone was purchased from TIB Molbiol (Germany). It was selected for the study because of its proven safety in ovo (11). The ligand was dissolved in sterile phosphate-buffered saline (PBS, $\mathrm{pH}$ 7.4) to its working concentrations.

Experimental design. The embryonated eggs were randomly allocated into three groups. On day 18 , the chicken embryos were administered in ovo $\mathrm{CpG}$ ODN (directly into the yolk sac): $10 \mu \mathrm{g}$ in $200 \mu \mathrm{L}$ PBS/egg for group 1 and $50 \mu \mathrm{g}$ CpG ODN in $200 \mu \mathrm{L}$ PBS/egg for group 2. The third group of chicken eggs was administered $200 \mu \mathrm{L}$ of PBS as above. Eggs from all groups were left to hatch. At 1, 2, 5, and 10 days post-hatching (dph), five chicks from each group were euthanised and the spleen was immediately collected for RNA isolation.

RNA extraction. The received organ samples were homogenised in PBS $(10 \% \mathrm{w} / \mathrm{v})$ with antibiotics $(2,000 \mathrm{U} / \mathrm{mL}$ of penicillin and $2 \mathrm{mg} / \mathrm{mL}$ of streptomycin). Total RNA was isolated from the homogenised spleens using RNeasy Mini kit (Qiagen, Germany) according to the manufacturer's protocol. Total RNA was eluted in $50 \mu \mathrm{L}$ of RNase-free water and stored at $-70^{\circ} \mathrm{C}$ until used. The concentration and quality of the obtained RNA was assessed by the ratio of the optical densities at $260 \mathrm{~nm}$ and $280 \mathrm{~nm}$ wavelengths using a NanoDrop 2000 spectrophotometer (Thermo Scientific, USA).

Quantitative RT-PCR. Expression of cytokine genes was assessed by real-time quantitative reverse transcription PCR (qRT-PCR) using a QuantiTect Probe RT-PCR Kit (Qiagen) with primers and probes previously described $(10,17,22,28,29)$. Primers and probes were synthesised by Genomed (Poland) and their specific sequences are shown in Table 1. All PCR reactions were performed using the Applied Biosystems 7500 system (Applied Biosystems, USA) with the following cycle profile: one cycle of $50^{\circ} \mathrm{C}$ for $30 \mathrm{~min}$ and one cycle of $95^{\circ} \mathrm{C}$ for $15 \mathrm{~min}$, followed by $95^{\circ} \mathrm{C}$ for $15 \mathrm{sec}$ and $60^{\circ} \mathrm{C}$ for $60 \mathrm{sec}$ for 40 cycles. The expression of the housekeeping gene ( $\beta$-actin) was used for normalisation of data. The assays were performed in duplicate including no-template controls. The median and mean values were calculated and the expression levels of IL- 6 , IL-10, IFN- $\alpha$, IFN- $\beta$, and IFN- $\gamma$ were described as $2^{-\Delta \Delta C t}$. 
Statistical analysis. Statistical analysis of the obtained results was performed using Statistica 6.0. Arithmetic means, standard deviations (SD), and minimum and maximum values were calculated for the studied groups. Non-parametric tests were used to analyse the results. The Kruskal-Wallis test was used in order to compare the level of expression values (RQ) among all of the studied groups, while the MannWhitney $U$ test compared two independent groups. Comparisons were considered significant at $\mathrm{P} \leq 0.05$.

\section{Results}

The kinetics of IFN $\alpha$ expression in the spleens of CpG10 and CpG50 ODN-administered birds compared to control birds are shown in Fig. 1. IFN $\alpha$ transcripts were up-regulated on $1 \mathrm{dph}$ for both doses of ligand, but only the increase in the CpG10 group was statistically significant $(\mathrm{P}<0.05)$. On 2 and $5 \mathrm{dph}$, transcript levels in both groups were down-regulated compared to the PBS-treated group, but only the low dose of ligand on $5 \mathrm{dph}$ significantly inhibited IFN $\alpha$ expression $(\mathrm{P}<0.05)$. In contrast, on $10 \mathrm{dph}$ the obtained results did not differ significantly between the PBS control group and the $\mathrm{CpG}$-stimulated groups $(\mathrm{P}>0.05)$.

The IFN- $\beta$ mRNA expression level after $\mathrm{CpG}$ administration was not affected significantly on $1 \mathrm{dph}$, whereas $\mathrm{CpG}$ treatment resulted in a significant $(\mathrm{P}<0.05)$ decrease in IFN- $\beta$ expression in the CpG50 group on $2 \mathrm{dph}$ when compared with the control group. No significant differences between gene expression levels on $5 \mathrm{dph}$ were noted, whereas on $10 \mathrm{dph}$ IFN- $\beta$ expression increased in both treated groups; however, only the lower dose of ligand resulted in a statistically significant difference (Fig. 2).

Table 1. Primers and probes used in the study

\begin{tabular}{|c|c|c|}
\hline Target gene & Sequence (5'-3') & Reference \\
\hline \multirow{3}{*}{ IL-6 } & F: GCTCGCCGGCTTCGA & \multirow{3}{*}{ Kaiser et al. (17) } \\
\hline & R: GGTAGGTCTGAAAGGCGAACAG & \\
\hline & Probe: AGGAGAAATGCCTGACGAAGCTCTCCA & \\
\hline \multirow{3}{*}{ IL-10 } & F: CATGCTGCTGGGCCTGAA & \multirow{3}{*}{ Kumar et al. (22) } \\
\hline & R: CGTCTCCTTGATCTGCTTGATG & \\
\hline & Probe: CGACGATGCGGCGCTGTCA & \\
\hline \multirow{3}{*}{ IFN- $\alpha$} & F: GACAGCCAACGCCAAAGC & \multirow{3}{*}{ Eldaghayes et al. (10) } \\
\hline & R: GTCGCTGCTGTCCAAGCATT & \\
\hline & Probe: CTCAACCGGATCCACCGCTACACC & \\
\hline \multirow{3}{*}{ IFN- $\beta$} & F: CCTCCAACACCTCTTCAACATG & \multirow{3}{*}{ Peroval et al. (28) } \\
\hline & R: TGGCGTGCGGTCAAT & \\
\hline & Probe: TTAGCAGCCCACACACTCCAAAACACTG & \\
\hline \multirow{3}{*}{ IFN- $\gamma$} & F: GTGAAGAAGGTGAAAGATATCATGGA & \multirow{3}{*}{ Kaiser et al. (17) } \\
\hline & R: GCTTTGCGCTGGATTCTCA & \\
\hline & Probe: TGGCCAAGCTCCCGATGAACGA & \\
\hline \multirow{3}{*}{$\beta$-actin } & F: CATCCTCACCCTGAAGTACC & \multirow{3}{*}{ Vora et al. (39) } \\
\hline & R: GCTCATTGTAGAAGGTGTGG & \\
\hline & Probe: CACGGCATCGTCACCAACTG & \\
\hline
\end{tabular}

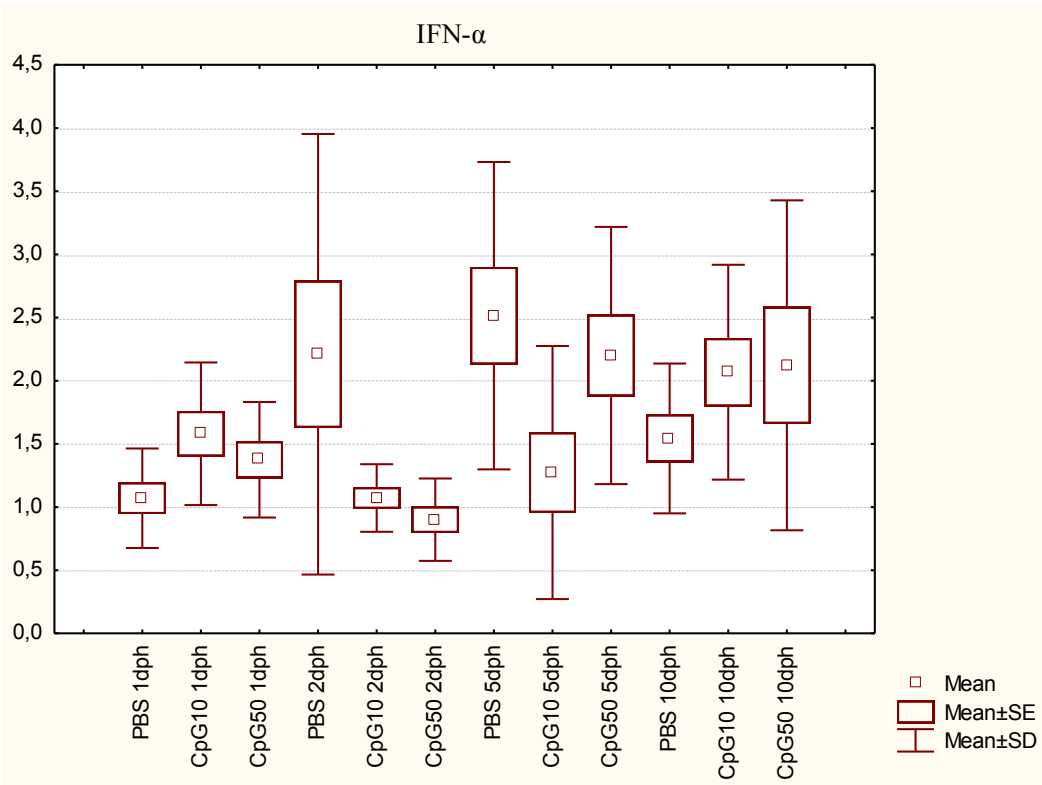

Fig. 1. IFN- $\alpha$ expression in the spleen of chicks at $1,2,5$, and $10 \mathrm{dph}$ after in ovo CpG ODN treatment 
IFN- $\gamma$ transcript levels in both CpG-stimulated groups were not statistically different from the PBS treated control group on $1 \mathrm{dph}$. On 2, 5, and $10 \mathrm{dph}$, IFN- $\gamma$ expression was increased in $\mathrm{CpG}$-treated chicks compared with the control group $(\mathrm{P}<0.05)$. Both doses of ligands raised IFN- $\gamma$ expression to a threefold higher level on $2 \mathrm{dph}$, while on $5 \mathrm{dph}$ the lower dose influenced its production more strongly, resulting in an almost 2.5 times greater expression in comparison with the PBS-treated group $(\mathrm{P}<0.05)$. The higher dose resulted in a nearly 1.5 -fold increase $(\mathrm{P}<0.05)$. The highest impact was noted on day 10 in the $\mathrm{CpG} 50$ group, where the expression increased more than 5 -fold, whereas the increase in the CpG10 group was not significant (Fig. 3).
The transcriptional responses of relevant inflammatory interleukins (IL-6 and IL-10), which are suggestive of TLR stimulation, were also examined.

Both doses of $\mathrm{CpG}$ treatment significantly $(\mathrm{P}<0.05)$ decreased IL-6 mRNA level on 1 dph. IL-6 expression in both groups was about 5 times lower than in the control group. On $2 \mathrm{dph}$ a significant increase $(\mathrm{P}<0.05)$ was found in the CpG10 group, while the higher dose of ligand did not lead to any significant differences. On day 5, in contrast, IL-6 expression decreased significantly after administration of the higher dose of $\mathrm{CpG}(\mathrm{P}<0.05)$. Finally, there were no differences between the treated groups and the control group regarding IL-6 expression on $10 \mathrm{dph}(\mathrm{P}<0.05)$ (Fig. 4).

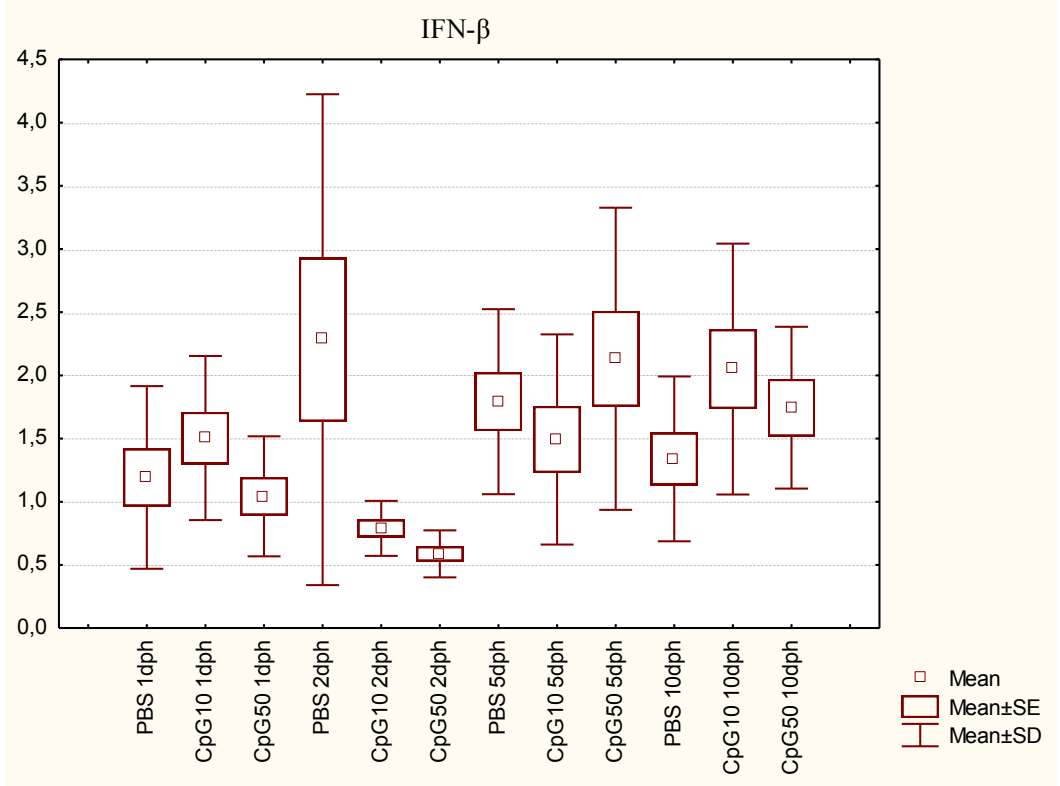

Fig. 2. IFN- $\beta$ expression in the spleen of chicks at $1,2,5$, and $10 \mathrm{dph}$ after in ovo $\mathrm{CpG}$ ODN treatment

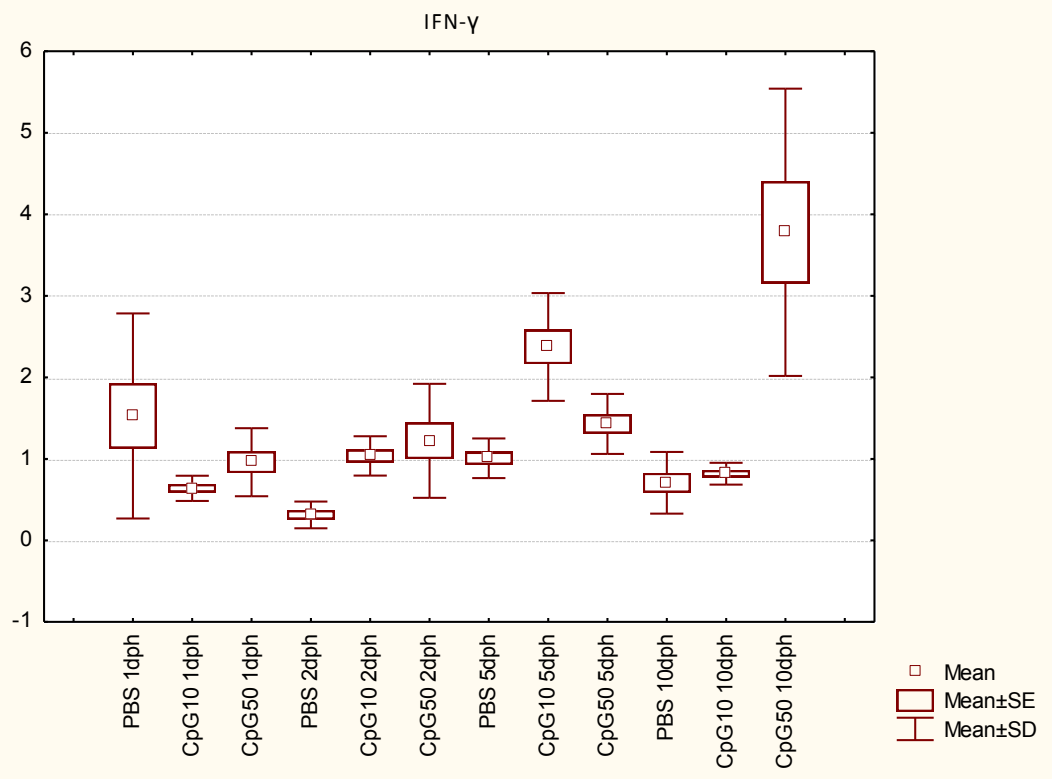

Fig. 3. IFN- $\gamma$ expression in the spleen of chicks at $1,2,5$, and $10 \mathrm{dph}$ after in ovo $\mathrm{CpG}$ ODN treatment 


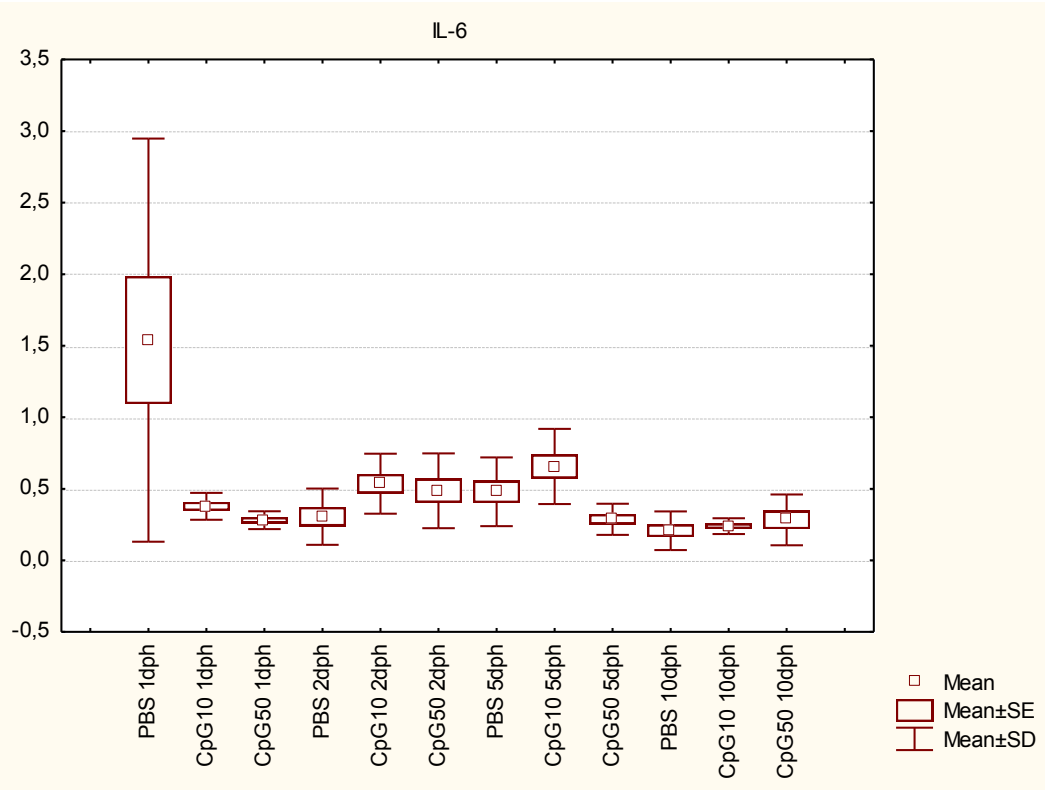

Fig. 4. IL-6 expression in the spleen of chicks at 1, 2, 5, and $10 \mathrm{dph}$ after in ovo $\mathrm{CpG}$ ODN treatment

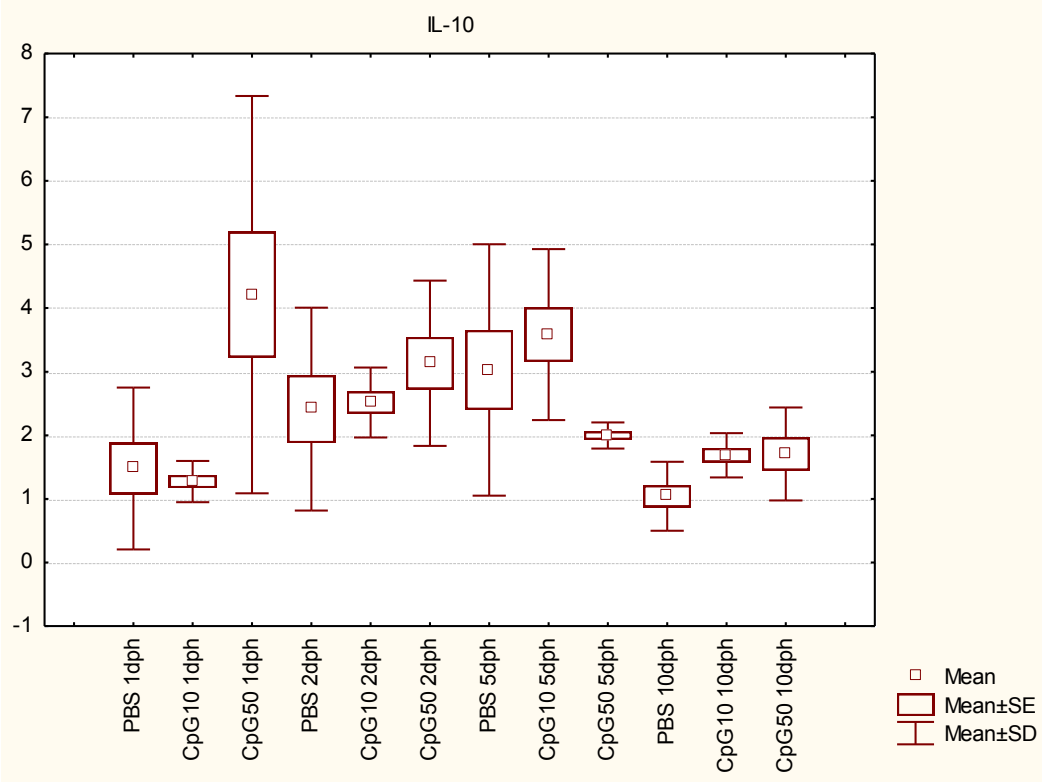

Fig. 5. IL-10 expression in the spleen of chicks at $1,2,5$, and $10 \mathrm{dph}$ after in ovo $\mathrm{CpG}$ ODN treatment

Lastly, IL-10 mRNA expression was significantly up-regulated by 3 times on $1 \mathrm{dph}$ in the spleen from the high-dose-CpG-treated group $(\mathrm{P}<0.05)$ compared to the PBS-treated group. Interestingly, the lower dose of $\mathrm{CpG}$ did not cause any significant differences $(\mathrm{P}>0.05)$. On 2 and $5 \mathrm{dph}$, no differences between the $\mathrm{CpG}$ and control groups were observed. However, on $10 \mathrm{dph}$ transcript levels in both $\mathrm{CpG}$-treated groups increased significantly compared to the control group $(\mathrm{P}<0.05)$. The results are presented in Fig. 5.

\section{Discussion}

Knowledge of the molecular and functional aspects of TLRs is essential for a better understanding of the immune system and resistance to diseases in birds. In addition, it provides valuable information on the evolution of the immune system of vertebrates. TLR signalling in chickens has several unique properties, both in terms of specificity of TLR ligand complex formation and signalling pathway activation. Bearing in mind the current extremely rapid expansion of the poultry industry and simultaneous reduction in the use of medications, there is a great need to develop new strategies for prevention and control of diseases that affect profitability. This also includes the search for new drugs and immunomodulatory agents to provide alternatives to the ones currently in use.

In our study we have chosen the TLR21 receptor, as its stimulation with the suitable ligand can 
modulate the immune system of chickens through production of type I and II interferons (5).

Type I interferons (IFN- $\alpha$ and IFN- $\beta$ ) have antiviral activity and increase MHC class I molecule expression. They are also able to activate both macrophages and natural killer (NK) cells. It is an essential element involved in protecting against multiple viral pathogens. They not only enhance the expression of the interferon-inducible genes, but also inhibit the transcription and translation of the virus and promote apoptosis in infected cells (30). Type II interferon (IFN- $\gamma$ ) is a pleiotropic cytokine that participates in most stages of the inflammatory and immune responses. Its antiviral activity is enhanced in combination with type I interferons (31). Type II IFNs associated with $\mathrm{T}_{\mathrm{H}} 1$ response also exhibit antiviral properties, partly through $\mathrm{NK}$ and $\mathrm{CD} 8+\mathrm{T}$ cell activation. These cells show antiviral activity through targeted release of the cytotoxic granules towards infected cells, thereby promoting apoptosis. Therefore, CpG ODN, which induces a $T_{H} 1$ response in chickens, proved to be effective in preventing infection with various viral pathogens, including avian influenza and infectious bronchitis viruses $(3,8,27)$. IL-6, as the proinflammatory cytokine, plays an important role in both the innate and adaptive immune systems and induces inflammatory responses during the disease. It promotes antibody production by B cells and switches monocyte differentiation from dendritic cells to macrophages (19). IL-10 is an anti-inflammatory cytokine with regulatory functions (16). It downregulates activated dendritic cells and macrophages and, moreover, suppresses Th1 and Th2 responses (20).

Our data clearly demonstrate that immune response induction after $\mathrm{CpG}$ ODN in ovo administration in post-hatching chicken spleen has some similarities with the incidences observed and presented previously. CpG ODN treatment in mammals was shown to rapidly up-regulate IFN- $\alpha$, IFN- $\gamma$, IL- $1 \beta$, IL-6, IL-12, and IL-18 mRNAs $(19,21)$. Up-regulation of type I IFNs occurs during early stages of viral infection of the cells, as well as in plasmacytoid dendritic cells stimulated by TLR ligands (9). Class B CpG ODN, as used in our study, is a potent stimulator for B cells, and thus preferentially induces cytokines other than IFNs of type 1 (2). However, previous studies showed a slight increase in IFN- $\alpha$ mRNA expression in mammals and chickens after administration of class B CpG ODN (20, 21). Furthermore, this type of alterations in the expression of type I IFNs may affect the antiviral activity of IFN- $\gamma$. We also noted slight alterations of IFN- $\alpha$ and IFN- $\beta$ mRNA. These changes were ambiguous (an initial increase, then a decrease and again an increase on $10 \mathrm{dph}$ ). These puzzling differences may arise from the kinetics of type I IFN expression on different days post-hatching in the control group or the different times when expression was measured. In any case, our results confirm the above-mentioned reports that class $\mathrm{B}$ CpG ODN rather weakly induces type I IFN.

Generally, a significant increase in IFN- $\gamma$ mRNA expression at almost all time points for both doses of CpG ODN was observed. Such up-regulation of IFN- $\gamma$ mRNA level corresponds with the previously reported expression of this cytokine in the spleen and bursal cells of one-day-old chicks treated with CpG ODN 2007 (27). Similarly, chicken PBMCs and macrophages stimulated with different $\mathrm{CpG}$ ODNs in vitro have shown a significant induction of IFN- $\gamma$ mRNAs (12). These changes of IFN- $\gamma$ in the spleen may result from the strong TLR-mediated B cell response. Interestingly, suggested by Sekellick et al. (31), a correlation may exist between a drastic increase in IFN- $\gamma$ and changes in IFN- $\alpha$ and IFN- $\beta$ expression on $10 \mathrm{dph}$.

IL-6 is a proinflammatory cytokine secreted by the immune cells after stimulation and pathogen infections (24). Again, as in the case of IFN- $\beta$, changes observed in IL-6 expression were ambiguous, being different for each dose. Our results are not consistent with previous publications. The absence of rapid induction of IL-6 mRNA expression in neonatal chickens in our study differs from the significant induction of this cytokine in chicken embryos and other animal species as described in the literature $(20,21)$. Furthermore, an increase in IL-6 mRNA expression was observed in in vitro studies in chicken splenocytes in response to CpG ODN (15). This suppression of IL-6 gene expression in our experiment on $1 \mathrm{dph}$ may suggest an anti-inflammatory role of $\mathrm{CpG}$ ODN 2007. In the above mentioned studies, the expression of IL- 6 was measured over periods from a few to a dozen hours after ligand administration. In our study, to check the length of changes in IL-6 expression, it was measured at longterm intervals in neonatal birds after in ovo $\mathrm{CpG}$ ODN application. In addition, these results may be the consequence of differences in constitutive expression of the TLR 21 between the chickens used in the study. Our previous data (unpublished) showed that TLR21 expression in 3-week-old SPF chicks was significantly higher than in broilers. Therefore, TLR21 stimulation with its ligand can also have a different course and trigger different effects. Moreover, it was also observed that the expression of some of the immune response genes varied significantly between different chicken organs during viral infection (35). A similar mechanism could exist during TLR stimulation.

Previous studies suggest that in mammals, expression of IL-10 down-regulates CpG ODN-induced inflammation by its influence on the expression of other cytokines, e.g. IL-12 (40). We also observed an increase in IL-10 mRNA expression in response to CpG ODN in ovo administration. This is in accordance with previous reports that showed a significant increase in the expression of IL-10 mRNA in chickens at early time points after administration of CpG-ODN (36). Our results are also in agreement with previous in vitro studies that implied IL-10 production by B cells, 
dendritic cells, and thrombocytes in response to $\mathrm{CpG}$ ODN $(23,34)$. Looking at the cytokine profile and earlier reports it seems that IL-10 expression may undergo major changes a few hours post-administration of CpG ODN.

In conclusion, we have shown that in ovo administration of class $\mathrm{B} \mathrm{CpG} \mathrm{ODN}$ has the ability to induce cytokine responses in neonatal chicken spleen. This study is the first step in defining the antiviral role of $\mathrm{CpG}$ ODN administrated via in ovo route. In addition, we confirmed the safety of $\mathrm{CpG}$ ODN in ovo use to enhance neonatal immunity without inducing disease pathology. Its administration on embryonic day 18 had some impact for at least 10 days after hatching. However, further studies should be performed to characterise the expression of other immune response genes. There is a need to correlate the significant changes in cytokine expression observed in our study with any real protection of chickens after the challenge. It is important to examine the effect of combined administration of $\mathrm{CpG}$ ODN and other TLR ligands, as it was reported that simultaneous chicken monocyte treatment with $\mathrm{CpG}$ ODN and poly I:C (TLR3 ligand) caused a synergistic effect in up-regulation of IFN- $\gamma$ and IL-10 in comparison with the treatment using individual ligands (13).

Conflict of Interests Statement: The authors declare that there is no conflict of interests regarding the publication of this article.

Financial Disclosure Statement: This work was funded by the KNOW (Leading National Research Centre) Scientific Consortium "Healthy Animal - Safe Food", the Polish Ministry of Science and Higher Education resolution No. 05-1/KNOW2/2015.

Animal Rights Statement: All procedures requiring the use of embryonated eggs and hatched chicks were approved by the Second Local Ethics Committee of Animal Experimentation in Lublin (University of Life Sciences in Lublin, Poland) in accordance with the European and national regulations on animal experiments and welfare.

\section{References}

1. Albigier B., Dahlberg S., Henriques-Normark B., Normark S.: Role of the innate immune system in host defence against bacterial infections: focus on the Toll-like receptors. J Intern Med 2007, 261, 511-528.

2. Asselin-Paturel C., Trinchieri G.: Production of type I interferons: plasmacytoid dendritic cells and beyond. J Exp Med 2005, 202, 461-465.

3. Barjesteh N., Shojadoost B., Brisbin J.T., Emam M., Hodgins D.C., Nagy É., Sharif S.: Reduction of avian influenza virus shedding by administration of Toll-like receptor ligands to chickens. Vaccine 2015, 33, 4843-4849.

4. Brownlie R., Allan B.: Avian toll-like receptors. Cell Tissue Res 2011, 343, 121-130.
5. Callison S.A., Hilt D.A., Boynton T.O., Sample B.F., Robison R., Swayne D.E., Jackwood M.W.: Development and evaluation of a real-time Taqman RT-PCR assay for the detection of infectious bronchitis virus from infected chickens. J Virol Methods 2006, 138, 60-65.

6. Cavanagh D., Gelb J.J.: Infectious bronchitis. In: Diseases of poultry, edited by Y.M. Saif, Blackwell Publishing, Ames, Iowa 2008, pp. 117-136

7. Chrząstek K., Wieliczko A.: Characterization of oligodeoxynucleotides containing $\mathrm{CpG}$ motifs, their effects on immune cells, and their potential for use in human and veterinary medicine. Med Weter 2010, 66, 242-245.

8. Dar A., Potter A., Tikoo S., Gerdts V., Lai K., Babiuk L.A., Mutwiri G.: CpG oligodeoxynucleotides activate innate immune response that suppresses infectious bronchitis virus replication in chicken embryos. Avian Dis 2009, 53, 261-267.

9. Doly J., Civas A., Navarro S., Uze G.: Type I interferons: expression and signalization. Cell Mol Life Sci 1998, 54, 1109-1121.

10. Eldaghayes I., Rothwell L., Williams A., Withers D., Balu S., Davison F., Kaiser P.: Infectious bursal disease virus: strains that differ in virulence differentially modulate the innate immune response to infection in the chicken bursa. Viral Immunol 2006, $19,83-91$.

11. Gomis S., Babiuk L., Allan B., Willson P., Waters E., Ambrose N., Hecker R., Potter A.: Protection of neonatal chicks against a lethal challenge of Escherichia coli using DNA containing cytosine-phosphodiesterguanine motifs. Avian Dis 2004, 48, 813-822.

12. He H., Crippen T.L., Farnell M.B., Kogut M.H.: Identification of $\mathrm{CpG}$ oligodeoxynucleotide motifs that stimulate nitric oxide and cytokine production in avian macrophage and peripheral blood mononuclear cells. Dev Comp Immunol 2003, 27, 621-627.

13. He H., Genovese K.J., Swaggerty C.L., Mackinnon K.M., Kogut M.H.: Co-stimulation with TLR3 and TLR21 ligands synergistically up-regulates Th1-cytokine IFN- $\gamma$ and regulatory cytokine IL-10 expression in chicken monocytes. Dev Comp Immunol 2012, 36, 756-760.

14. He H., Genovese K.J., Swaggerty C.L., Nisbet D.J., Kogut M.H.: In vivo priming heterophil innate immune functions and increasing resistance to Salmonella Enteritidis infection in neonatal chickens by immune stimulatory $\mathrm{CpG}$ oligodeoxynucleotides. Vet Immunol Immunopathol 2007, 117, 275-283.

15. Jenkins K., Lowenthal J.W., Kimpton W., Bean G.D.: The in vitro and in ovo responses of chickens to TLR9 subfamily ligands. Dev Comp Immunol 2009, 33, 660-667.

16. Kaiser P.: The long view: a bright past, a brighter future? Forty years of chicken immunology pre- and post-genome. Avian Pathol 2012, 41, 511-518.

17. Kaiser P., Rothwell L., Galyov E.E., Barrow P.A., Burnside J., Wigley P.: Differential cytokine expression in avian cells in response to invasion by Salmonella typhimurium, Salmonella enteritidis, and Salmonella gallinarum. Microbiology 2000, 146, 3217-3226.

18. Keestra A.M., de Zoete M.R., Bouwman L.I., van Putten J.P.M.: Chicken TLR21 is an innate CpG DNA receptor distinct from mammalian TLR9. J Immunol 2010, 185, 460-467.

19. Klinman, D.M., Yi A.K., Beaucage S.L., Conover J., Krieg A.M.: CpG motifs present in bacteria DNA rapidly induce lymphocytes to secrete interleukin 6, interleukin 12, and interferon gamma. Proc Natl Acad Sci U.S.A. 1996, 93, 2879-2883.

20. Krieg A.M., Efler S.M., Wittpoth M., Al Adhami M.J., Davis H.L.: Induction of systemic TH1-like innate immunity in normal volunteers following subcutaneous but not intravenous administration of CPG 7909, a synthetic B-class CpG oligodeoxynucleotide TLR9 agonist. J Immunother 2004, 27, 460-471.

21. Krieg A.M.: CpG motifs in bacterial DNA and their immune effects. Annu Rev Immunol 2002, 20, 709-760. 
22. Kumar S., Buza J.J., Burgess S.C.: Genotype-dependent tumor regression in Marek's disease mediated at the level of tumor immunity. Cancer Microenviron 2009, 2, 23-31.

23. Lenert P., Brummel R., Field E.H., Ashman R.F.: TLR-9 activation of marginal zone $\mathrm{B}$ cells in lupus mice regulates immunity through increased IL-10 production. J Clin Immunol 2005, 25, 29-40.

24. Li C.K., Seth R., Gray T., Bayston R., Mahida Y.R., Wakelin D.: Production of proinflammatory cytokines and inflammatory mediators in human intestinal epithelial cells after invasion by Trichinella spiralis. Infect Immun 1998, 66, 2200-2206.

25. Mackinnon K., He H., Swaggerty C., McReynolds J., Genovese K., Duke S., Nerren J., Kogut M.: In ovo treatment with $\mathrm{CpG}$ oligodeoxynucleotides decreases colonization of Salmonella Enteriditis in broiler chickens. Vet Immunol Immunopathol 2009, 127, 371-375.

26. Medzhitov R.: Toll-like receptors and innate immunity. Nat Rev Immunol 2001, 1, 135-145.

27. Patel B.A., Gomis S., Dar A., Willson P.J., Babiuk L.A., Potter A., Mutwiri G., Tikoo S.K.: Oligodeoxynucleotides containing CpG motifs (CpG-ODN) predominantly induce Th1type immune response in neonatal chicks. Dev Comp Immunol 2008, 32, 1041-1049.

28. Peroval M.Y., Boyd A.C., Young J.R., Smith A.L.: A critical role for MAPK signalling pathways in the transcriptional regulation of Toll like receptors. PLoS ONE 2013, 8, e51243. doi:10.1371/journal.pone.0051243.

29. Pulendran B., Kumar P., Cutler C.W., Mohamadzadeh M., Van Dyke T., Banchereau J.: Lipopolysaccharides from distinct pathogens induce different classes of immune responses in vivo. J Immunol 2001, 167, 5067-5076.

30. Samuel C.E.: Antiviral actions of interferons. Clin Microbiol Rev 2001, 14, 778-809.

31. Sekellick M.J., Lowenthal J.W., O'Neil T.E., Marcus P.I.: Chicken interferon types I and II enhance synergistically the antiviral state and nitric oxide secretion. J Interferon Cytokine Res 1998, 18, 407-414.
32. Shinya K., Ito M., Makino A., Tanaka M., Miyake K., Eisfeld A.J., Kawaoka Y.: The TLR4-TRIF pathway protects against H5N1 influenza virus infection. J Virol 2012, 86, 19-24.

33. St Paul M., Brisbin J.T., Abdul-Careem M.F., Sharif S.: Immunostimulatory properties of Toll-like receptor ligands in chickens. Vet Immunol Immunopathol 2013, 152, 191-199.

34. St Paul M., Mallick A.I., Haq K., Orouji S., Abdul-Careem M.F., Sharif S.: In vivo administration of ligands for chicken toll-like receptors 4 and 21 induces the expression of immune system genes in the spleen. Vet Immunol Immunopathol 2011, 144, 228-237.

35. St Paul M., Mallick A.I., Read L.R., Villanueva A.I., Parvizi P., Abdul-Careem M.F., Nagy E., Sharif S.: Prophylactic treatment with Toll-like receptor ligands enhances host immunity to avian influenza virus in chickens. Vaccine 2012, 30, 4524-4531.

36. St Paul M., Paolucci S., Barjesteh N., Wood R.D., Schat K.A., Sharif S.: Characterization of chicken thrombocyte responses to Toll-like receptor ligands. PLoS One 2012, 7, e43381. doi: 10.1371/journal.pone.0043381.

37. Szczubełek P., Szeleszczuk P.: Synthetic oligodeoxynucleotides consisting of unmethylated cytosine-guanosine dinucleotides as immunostimulators for poultry. Med Weter 2009, 65, 823-826.

38. Taghavi A., Allan B., Mutwiri G., Van Kessel A., Willson P., Babiuk L., Potter A., Gomis S.: Protection of neonatal broiler chicks against Salmonella Typhimurium septicemia by DNA containing CpG motifs. Avian Dis 2008, 52, 398-406.

39. Vora P., Youdim A., Thomas L.S., Fukata M., Tesfay S.Y., Lukasek K., Michelsen K.S. Wada A., Hirayama T., Arditi M., Abreu M.T.: Beta-defensin-2 expression is regulated by TLR signaling in intestinal epithelial cells. J Immunol 2004, 173, 5398-5405.

40. Yi A.K., Yoon J.G., Yeo S.J., Hong S.C., English B.K., Krieg A.M.: Role of mitogen-activated protein kinases in $\mathrm{CpG}$ DNA-mediated IL-10 and IL-12 production: central role of extracellular signalregulated kinase in the negative feedback loop of the CpG DNA-mediated Th1 response. J Immunol 2002, 168, 4711-4720. 